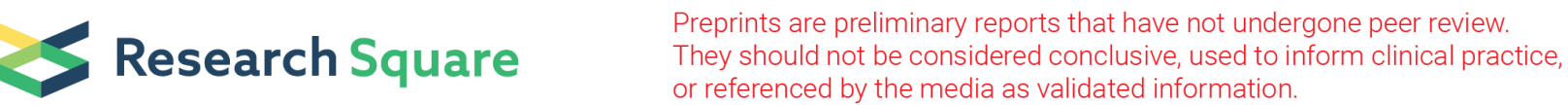

\section{Prevalence and Risk Factors of Active Trachoma among Rural Preschool Children in Wadla District, Northern Ethiopia: A Community Based Cross- Sectional Study}

Mesfin Wudu Kassaw ( $\nabla$ mesfine12a@gmail.com )

Woldia University https://orcid.org/0000-0002-6327-7723

Ayele Mamo Abebe

Debre Birhan Health Science College

Kirubel Dagnaw Tegegne

Wollo University

Mikiyas Amare Getu

Woldia University

Woldemichael Tadesse Bihonegn

Samara University

Research article

Keywords: Active Trachoma, Factors, Environmental Components, Villages, Water Supply

Posted Date: August 9th, 2019

DOl: https://doi.org/10.21203/rs.2.12538/v1

License: (c) (1) This work is licensed under a Creative Commons Attribution 4.0 International License.

Read Full License 


\section{Abstract}

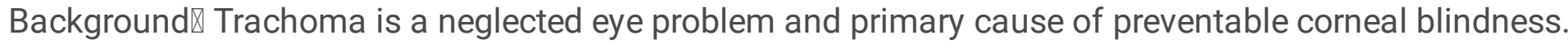
In endemic areas, initial infection occurs in early childhood, and recurrent infection progress to scarring and blindness. In the past four decades, GET2020 initiative eliminated Trachoma from developed countries through enhancements of hygiene and sanitation but still a problem of developing countries. Studies and reports also indicated the presence of high prevalence of Trachoma in Ethiopia and in the study area. Thus, the purpose of this study is to assess the prevalence and risk factors of active trachoma among rural preschool children in Wadla district, Ethiopia. Methods: A community based crosssectional study design was considered to gather data from 583 children using sample size determination, but 596 children were screened for signs of active trachoma because of the sampling procedure nature, cluster sampling technique. Wadla district has 150 rural villages, which are similar in topography and socio-demographic status. Based on rule of thumb 30 villages (clusters) were included for the data collection. An interview on socio-demographic data were collected by health informatics professionals using structured interview questioners, which were prepared through reviewing previous literatures and pretested in Meket Woreda. Eye examination was performed by Integrated Eye Care Workers who trained for one month for the purpose of trachoma screening by Carter center-Ethiopia. Results - The prevalence of active trachoma among rural pre-school children in Wadla district was 130 (21.8\%). Regarding risk factors, poor economic status (AOR (95\% Cl), (3.8 (1.3-11.4), being 37- 48 months old (AOR $(95 \% \mathrm{Cl}),(4.2$ (1.5-12.0), thatched house roof (AOR (95\%Cl), (4.4 (1.4-13.6), presence of fly in nearby home (AOR (95\% $\mathrm{Cl}), 4.6$ (2.1-9.9), once weekly face washing frequency (AOR (95\% Cl), 8.6 (2.5-29.3), unwashed face for longer than a week (AOR (95\% Cl), 10.6 (2.9-37.7), not using soap (AOR (95\% Cl), 4.5 (1.8-11.3), and absence of latrine (AOR $(95 \% \mathrm{Cl}), 5.1(2.0-12.9)$ have association with active trachoma. Conclusion: Environmental factors weigh other factors and this could capture the intention of policy makers to emphasize on the environmental components like sanitation including face cleanness to decrease the prevalence of trachoma

\section{Background}

Trachoma is a neglected eye problem and primary cause of preventable corneal blindness $[1,2]$. It is categorized as active trachoma (AT) and inactive types of trachoma [2-4]. In endemic areas, initial infection occurs in early childhood, and recurrent infection progresses to scarring and blindness $[5,6]$. Usually, trachoma is a disease of poverty, and poor hygiene [7-9], which mainly infect children [5], and adult women because of close and long-time contact with small children, who are the main pool of trachoma infection [10]. Globally, 60 to 80 million peoples were had been active trachoma with annual deaths of 500 and 2.3 million disability adjusted life years [11].

A study in Nigeria [12] disclosed the presence of flies on the face and absence of toilet in the compound as independent factors of active trachoma. A survey in 4 African countries 
revealed the prevalence of Trachomatous follicular was highest among children aged 2-5 years in Ethiopia and Niger [13].

Studies in Ethiopia reported that being female, having unclean face, not using soap, poor face washing habit, and absence of latrine as risk factors of active trachoma [14, 15]. A study in Gonder indicated being 1-5 years old had association with active trachoma[16]. Following World Health Organization's SAFE (Surgery, Antibiotic, Facial cleanness and Environmental change) strategy implementation through global elimination of trachoma (GET2020) initiative with a plan of elimination from the globe in 2020 [17]; Ethiopia launched VISION 2020 initiative in 2002 following this WHO recommendation [18].

Consequently, in the past four decades, using GET2020 initiative as weapon trachoma had been eliminated from developed countries particularly with enhancements of hygiene and sanitation but still a problem of developing countries [19].

The simple cases of trachoma can be treated by antibiotic and more complex cases can be treated with a simple surgery [20]. Irrespective of intensive SAFE implementation in Ethiopia, the prevalence in Amhara region, Wag Himra zone was 52.4\% [18, 21] and one newspaper reported that Wag Himra zone was attributable to the world's highest trachoma prevalence[22]. These indicate that the prevalence of Active trachoma in most part of Ethiopia [15, 23] and in the study area, Amhara region [24-26] is still a public health problem and needs frequent assessment.

\section{Methods}

\section{Study design and population}

A community based cross-sectional study design was used from March 11/2017 to April 26/2107. The population of Wadla district was 128,170 with 64,574 males and 63, 596 females. There were 28,414 households in this district and resulting an average of 4.51 persons per house ratio [27]. The source population are children aged 1-5 years and their care givers in 150 rural villages of Wadla district, whereas the study population are children aged 1-5 years and their care givers in 30 selected clusters or villages.

\section{Sampling Procedure}

Wadla district has 20 Kebeles with a total of 247 villages. Of these 150 were rural villages. While selecting study participants two stage sampling techniques were used. The first stage was selecting 30 of 150 rural clusters or villages as study population. The second phase was choosing 583 children within those 30 villages or cluster. The study includes all children aged 1 to 5 years from 499 households based on cluster sampling assumption (Figure 1). 


\section{Sample size determination}

The sample size estimated using single population proportional formula and got 583. The assumptions used was proportion of 35.7\% [12], 95\% CI, 5\% margin of error, 1.5 design effect and $10 \%$ non- response rate. It is calculated as

$$
\begin{aligned}
\mathrm{n}=(\underline{1.96}) & \underline{2}-\underline{(0.357 \mathrm{X} 0.643)}), \\
& (0.05)^{2} \\
\mathrm{n}= & \underline{3.8416 \mathrm{x} .229551}=352.7 \approx 353
\end{aligned}
$$

(0.0025)

After adding a design effect of 1.5, it gives $(353 \mathrm{X} 1.5)+353=529.5+52.95=882.45=583$

\section{Data collection tools and procedures}

The interview part like socio-demographic data were collected by diploma in health informatics professionals using structured interview questioners, which were prepared through reviewing previous literatures $[26,28]$.

Eye examining was performed by Integrated Eye Care Workers (IECWs) who trained for one month for the purpose of trachoma screening by Carter center-Ethiopia. The training was delivered using both pictures and live patients. Each of the trainer diagnosed 5 live patients and read 10 pictures of different active trachoma signs independently. The diagnosis and picture reading were assured by the trainers' weather they diagnosed correctly or not. While they were screening children, they initially observe the eyelashes and cornea to appreciate two of the inactive types of trachoma then eversion of the upper lid and inspection of the upper tarsal conjunctiva using WHO simplified grading scheme to identify the active stages using 2.5 times loupe magnifiers [4].

\section{Data Analysis}

Data were checked for normality using hosmer-lemeshow-goodness-of-fit, and then coded and entered into Epi-info version 7 and transferred to statistical package for social science version 23 for data analysis. Both bi-variable and multi - variable analysis was carried out. Potential co-linearity was considered and tested. Variables with P-value less than 0.05 in multivariable analysis were considered as statistically significant.

\section{Results}




\section{Socio - demographic characteristics of care-givers}

Although, the sample size was 583, a total of 596 preschool children from 499 households were screened for signs of active trachoma using cluster sampling technique. All the children aged 1 to 5 years from a single household were examined for trachoma. This causes to have 100\% response rate. All 499 households' children aged 1-5 years were included in the study. All 499 households were Amhara in ethnicity and were a follower of Ethiopian orthodox Christianity (Table 1).

\section{Environmental characteristics}

Households, which consume less than 20 litter of water per day were 180 (36.1\%) and 459 (92\%) households were walking $1 / 2 \mathrm{hr}$ to fetch water. Seventy-four percent (371) of the respondents were had private latrine in their nearby house whereas 243 (48.7\%) household's surrounding were had feces (Table S1).

Nearly, twenty nine percent of houses were had clean grass house roof, $26.7 \%$ had thatched corrugated iron roof, $27.5 \%$ had thatched grass roof and $16 \%$ were had a clean corrugated iron house roof

\section{Characteristics of children}

Off the total screened children for active trachoma 301 (50.5\%) were males and 295 (49.5\%) were females (Table 2).

\section{Prevalence of Trachoma}

The prevalence of active trachoma in Wadla district was 130 (21.8\%), [(95\%, CI), (18\%, 25\%)]. Of these 106 (81.5\%) was TF, 13 (10\%) was TI, and both TF and TI were 11 (8.5\%). There was no trachomatous scarring (TS), trachomatous trichiasis (TT), and corneal opacity CO).

Regarding sex of children, $56.2 \%$ female and $43.8 \%$ male children were had active trachoma.

The prevalence of active trachoma among 12 - 24 months old children was $2.3 \%$, of 25-36 months old was $10.8 \%$ and of $48-59$ months old was $29.2 \%$. 


\section{Risk Factors}

\section{Socio-demographic, personal and economic factors}

On bi-variable analysis poor economic status (COR (95\% CI), (4.638(2.353-9.143), being in 24-36 months old (COR (95\% CI), (.498 (.254-.975), educational status of fathers (COR (95\%CI), (1.696 (.845-3.404), educational status of mothers (COR (95\% CI), (2.962 (1.3206.647), MUAC of children < 13.9cm (COR (95\% CI), (1.696 (1.139-2.527) were had association with active trachoma. But on multi-variable analysis only poor economic status (AOR (95\% CI), (3.804 (1.267-11.424) and being in 37- 48 months old (AOR (95\% CI), (4.213 (1.475-12.034) increase the odds of active trachoma (Table S2).

\section{Environmental factors}

The multi variable analysis indicated thatched grass house roof (AOR (95\%CI), (4.402 (1.425-13.597), and presence of fly near to home increase the odds of active trachoma (Table 3).

\section{Discussion}

The prevalence of Active Trachoma in rural Wadla district among rural preschool children was $21.8 \%,[(95 \%, C I),(18 \%, 25 \%)]$. This puts the district on the second stage of World Health Organization threshold [17]. The research indicates SAFE strategy were unsuccessful in the last 7 years in Wadla district [29]. There are also studies [14, 15, 25, 28] that reported the prevalence of Active Trachoma above $20 \%$. It displays that trachoma is still a public health problem. The finding also agreed with previous reports and researches $[15,30]$ done in Africa and different parts of Ethiopia, such as the $6^{\text {th }}$ meeting report of WHO, that reported the prevalence of active trachoma in Algeria was 26\%, in Burkina Faso was 26.9\% [30] and a study in different regions of Ethiopia reported the prevalence as $22.6 \%$ in Somali region, in Tigray region $26.5 \%$ and $19.1 \%$ in Gambela region [15].

The finding of this study was lower than that of the studies done in southern Sudan was 64.5\% [31], in Egypt was 49\% [32], and in Nigeria was 35.7\% [12]. This variation might be the result of different study period and difference in health care service. Because this study conducted after 8 years in relative to these comparing studies. In addition, intensive SAFE strategy implementation in all endemic countries were reached peak in the past seven years. Similarly, the finding is lower than many studies 59.2\% [33], 32.4\%, 42.4\%, 56.9\% [28], 62.6\% [14], 40.1\% [23] conducted before 2015. Therefore, the current reduction of active trachoma in the study area and in other endemic areas across the continent [16] 
Africa, is mainly the result of SAFE strategy and improved socio-demographic characteristics. But, the finding of this study was higher than a study conducted in 2016 in Gonder, Ethiopia (12.1\%) [16]. The difference might be because of different study population, level of urbanization and difference in infrastructure. This study done only in rural children aged 6 moths to 5 years but the comparative one is in urban children aged 1 - 9 years old [16].

The prevalence of TI in this study area was 3.4\% agreed with the study conducted in South Wollo zone was 4.3\% [34], and lower than the study in South Gonder zone was 7.0\% [34]. This discrepancy might be the result of different study subjects and this discrepancy agreed with the statement that the progress of trachoma from one stage to other stage is gradual and increases as age increases [2].

The study showed washing face once weekly (AOR (95\%CI), 8.686 (2.577-29.277) and unwashed face for longer than a week (AOR (95\% CI), 10.592 (2.974-37.727) as well as presence of fly in near home (AOR (95\% CI), 4.603 (2.138-9.911) had positive association with active trachoma, which is in line with a study conducted in southern Sudan, and Gonder, Ethiopia [35, 36]. Absence of toilet (AOR (95\% CI), 5.089 (2.011-12.876) also had positive association with active trachoma, which is similar with a study conducted in Nigeria, Egypt, north-west Ethiopia, and Gonder [34, 35, 37, 38]. The presence of human excreta near to home (AOR (95\%CI), 5.089 (2.011-12.876) was also increase the odds of active trachoma. This is supported with a study conducted in Dera district, Ethiopia [39]. This study also reported not using soap while washing face were increasing the odds of acquiring active trachoma (AOR (95\%CI) 4.493 (1.788-11.290) and it is supported by the study conducted in Dessie city, Ethiopia, and Gonder, Ethiopia [35, 40].

All of these positively risk factors agreed with a literature that trachoma is mainly attributed to environmental factors, sanitation and hygiene practice. The Bazaar vector, Musca Sorben is also proposed as major risk factor of trachoma, which is multiplied in open field human excreta. Therefore, the absence of latrine increase the occasion of fly multiplication sites and densities of fly and in turn causes active trachoma[41]. The poor habit of hygiene and sanitation as well as failure to use soap also contribute for the presence of ocular and nasal discharge on children's face, which open the opportunities for flies to contact with unclean face of those children.

Thatched grass house roof (AOR (95\% CI), 4.402 (1.425-13.597) had association with active trachoma, which is in line with a study done in central Ethiopia [42] and poor economic status (AOR (95\% CI), 3.804 (1.267-11.424) also increase the odds of active trachoma supported by the study done in Gonder, Ethiopia [35]. These association are also consistent with a literature that trachoma is a disease of poverty, overcrowding, and poor hygiene [8, 9].

\section{Conclusion}

The prevalence of trachoma is high in the study area. Environmental factors weigh other factors and this could capture the intention of policy makers to emphasize on the 
environmental components like sanitation including face cleanness to decrease the prevalence of trachoma while caring preschool children.

\section{Abbreviations}

COR - Crude odd ratio, AOR- Adjusted odd ratio, CI - Confidence interval, AT-Active Trachoma, SAFE-Surgery, Antibiotics, Facial Cleanness, Environmental Changes, GET2020- Global elimination of Trachoma in 2020, WHO- World Health Organization, TTtrachomatous trichiasis, TF- trachomatous follicular, TI- trachomatous intense, TTtrachomatous trichiasis, CO- corneal opacity, MUAC-Mid upper arm circumference.

\section{Limitation}

- The study didn't take stool sample. Because of this the relation of active trachoma with sanitation and hygiene or intestinal parasitic infection is not established

- The lack of research on children aged 1 to 5 years impose us to discuss with researches done on children aged 1 to 9 years. This might decrease the reliability of the research.

\section{Declarations}

\section{Ethical Consideration}

Prior to the commencement of this study ethical approval letter was obtained from Mekelle University. The study protocol was evaluated and approved by the Health Research Ethics Review Committee [HRERC 0917/2017] of College of Health Sciences, Mekelle University. Written permission was also obtained from Woldia zonal health department and send to Wadla district health office. The Woreda health office was also approved the permission got from North Wollo zone health department. Finally, written consent was taken from children's parents or care givers for interview and eye screening after explaining the purpose of the study to the care givers of children. Confidentiality was also maintained by omitting the name and personal identification of respondents (both children and care givers) because it was not compelled to the study.

STROBE statement: the manuscript is reported in a format which adheres to STROBE guidelines, (http://www.strobe-statement.org/) for reporting observational research according to BioMed Central editorial policies (http://www.biomedcentral.com/submissions/editorial-policies\#standards+of+reporting).

\section{Consent for Publication}


Participants (care givers) were informed and gave their written consent to publish the findings in repeatable international journals.

\section{Acknowledgment}

Our deepest gratitude go to department of nursing, college of health science of Mekelle University for the provision of main fund and Wadla district health office for providing additional fund. We are also grateful to Mr. Semagn Gubala, Mr. Mulugeta Wodaje, Mr. Matiyas Munye, Mr. Melak Menberu, and Mr. Eskezaw Abebe for their unrestricted support for the completion of this work either by collecting data, revising or commenting the inquiry draft. Lastly, we are grateful to the community of the study area and all the respondents whose participation made possible the collection of the data set used in this work.

\section{Funding}

This study was supported by Mekelle University, College of Health sciences and Wadla district health office, Northern Ethiopia. Both of the funders had no any role like on data collection, data analysis, report wrting and etc but they waged all the financial expenses.

\section{Availability of data and materials}

The raw material supporting the conclusions of this research will be available to researchers needing the data to use for non-commercial purposes.

\section{Author Contributions}

Conceived the title and designed the study: MWK, and AMA. Field study: MWK, KDT. WMT, MAG, AMA. Analyzed the data: MWK, AMA, KDT, MAG, WMT. Critically revising the work: MWK, AMA, KDT, MAG. Writing the final paper: MWK, WMT, AMA and KDT. Finally, all authors have read and approved the final version of this manuscript"

\section{Competing interests}

The authors declare that they have no any conflicting of interests 


\section{References}

1. Jawetz, Melnick, and Adelberg. Lange Medical Microbiology. $24^{\text {th }}$ edition. United States of America, McGraw-Hill. 2007, ISBN / ASIN: 0071476660. P 531

2. Victoria Francis and Virginia Turner. Achieving Community Support for Trachoma Control, A guide for district health work. The Edna McConnell Clark Foundation, New York and WHO. United States of America, Helen Keller International.1995. P 10.

3. Maggie Montgomery. Sustaining Trachoma Control and Elimination, the basis for environmental indicators in the certification of the elimination of blinding Trachoma. Water, Sanitation and Health, World Health Organization, Geneva, 2006.

4. David C W Mabey, Anthony W Solomon, Allen Foster. Trachoma seminar. Lancet, 2003. 362. Available from www.thelancet.com

5. Imtiaz A., Chaudhry, Yonca O., Arat and Waleed Al-Rashed.Trachoma and Conjunctivitis, Conjunctivitis - A Complex and Multifaceted Disorder. Prof. ZdenekPelikan (Ed.), INTECH open science. 2011. ISBN: 978-953-307-750-5. Available from:

http://www.intechopen.com/books/conjunctivitis-a-complex-andmultifaceteddisorder/trachoma-and-conjunctivitis

6. Hugh R Taylor. Trachoma, A blinding scourge from the bronze age to the twenty century. Centre for Eye Research, Australia, 2008.

7. J. Karimurio, M. Gichangi, D. R. Ilako, H. S. Adala, and P. Kilima. Prevalence of trachoma in six districts of Kenya. East African Medical JournaL. 2006. 83(4): P 5. 
8. D. Haddad. "The end game for blinding trachoma," World Ophthalmology News.2012.

9. Zerihun N. Impact of trachoma among rural Ethiopian women. Ethiopian Journal of Health sciences, 1998. 8(1): P 7.

10. WHO. Priority eye diseases, Main causes of visual impairment. WHO, 2010: P 14.

11. Peter J. Hotez. The development impact of the neglected tropical diseases (NTDs). United Nations, New York, Department of Economic and Social Affairs. Population Division, Expert Paper. 2011. 1.

12. C. Mpyet, M. Goyol and C. Ogoshi. Personal and environmental risk factors for active trachoma in children in Yobe state, north-eastern Nigeria. Tropical Medicine and International Health. 2010. 15(2): P 5.

13. Jonathan D., Jeremiah Ngondid, Sanoussi Bamanie, Yaya Kamissokof, Kadri Boubicarg, Benjamin C. Nimzing Jipj, Asrat Amniek, Tesfaye Teferim,, and Aryc W., Elizabeth A. Cromwell and Paul M. Emerson. Trachoma among children in community surveys from four African countries and implications of using school surveys for evaluating prevalence. International Health 2013. 5.

14. Berhane Y, Worku A, Bejiga A, Liknaw A, Wondu A, et al. Prevalence and causes of blindness and Low vision in Ethiopia. Ethiopian Journal of Health. 2007: 21. P. 5.

15. Yemane Berhane,Worku A., Abebe Bejiga, Liknaw Adamu, Wondu Alemayehu, Amir Bedri, Zegeye and Yilikal Adamu, Teshome Gebre, Tewodros, Emily West, Sheila West. Prevalence of Trachoma in Ethiopia. Ethiopian journal of Health Devevelopment. 2008.

16. Muluken Asres, Mulualem Endeshaw and MeleseYeshambaw. Prevalence and Risk Factors of Active Trachoma among Children in Gondar Zuria District, North Gondar, Ethiopia. Preventive medicine. 2016. 1 (1:5).

17. David Molyneux. Neglected tropical diseases. Community eye health. 2013: 26(82).

18. Budden FH. A report on blindness in Ethiopia. Geneva, WHO.

19. Mecaskey JW, Knirsch CA, Kumaresan JA, Cook JA. The possibility of eliminating blinding trachoma. Lancet Infect Dis. 2003: 3: P 7.

20. AMREF. Preventing and Treating Trachoma in rural Kenya, Kenya. Project Report to the Wolfson Group. 2011.

21. Zelalem Alamrew Anteneh. Prevalence of active trachoma and associated risk factors among children in Gazegibela district of Wagehemra Zone, Amhara region, Ethiopia: community-based cross-sectional study. BMC Tropical Diseases. Travel Medicine \& Vaccine. 2016: 2(5).

22. Hiwote Solomon. Emory Global Heath Institute, EMORY ETHIOPIA NEWSLETTER. November 2016.

23. Mariotti S., Pascolini D., Rose-Nussbaumer J. Trachoma: a global magnitude of a preventable cause of blindness. British Journal of Ophthalmology. 2009: 93: P 6. 
24. World Health Organization. Prevention of Blindness and Deafness. Report of the Eighth Meeting of the WHO Alliance for the Global Elimination of Blinding Trachoma. WHO, 2004.

25. Carter center. Prevalence and risk factors for malaria and trachoma in Ethiopia. A household cluster survey of trachoma prevalence and risk factors in Amhara region. Carter center, 2007.

26. Endale Berta (MD). Prevalence and risk factors of active trachoma among children of rural south Gonder, Ethiopia. Addis Ababa University, Thesis. 2004.

27. Centeral statistics agency, Ethiopian national census for Amhara 'region. 2007.

28. Alemayehu Mesfin. Assessing the prevalence of active trachoma among young children in relation to the implementation of safe strategy in Ebinat and East Belesa woreda, North West Ethiopia. Ethiopia, Addis Ababa University, Thesis, 2005.

29. Helen Hamilton, Yael Velleman. WASHing away blinding trachoma. WaterAid and sightsavers. 2013: P 4.

30. WHO. Report of the six meeting of WHO alliance for the global elimination of Blinding trachoma. WHO, Switzerland, Geneva, 2001.

31. Jeremiah Ngondi, Mark Reacher, Alice Onsarigo, Ibrahim Matende, Samson Baba, Carol Brayne, and James Zingeser. Prevalence of Risk Factors and Severity of Active Trachoma in Southern Sudan: An Ordinal Analysis. The American Society of Tropical Medicine and Hygiene. 2007: 77(1): P 7.

32. Paul Courtright, John Sheppard, Sandra Lane, AlySadek, Julius Schachter, Chandler R Dawson. Latrine ownership as a protective factor in inflammatory trachoma in Egypt. British Journal of Ophthalmology. 1991: 75: P 4.

33. Mengiste M. Mesfin. A Community-Based Trachoma Survey: Prevalence and Risk Factors in Tigray Region of Northern Ethiopia. Ophthalmic Epidemiology.2006: 13: P 11.

34. Jonathan D. King, Jeremiah Ngondid, Sanoussi Bamanie, Yaya Kamissokof. Novel approaches to evaluate the impact of SAFE strategy on trachoma and other neglected tropical diseases in Amhara Regional State, Ethiopia. 2014.

35. Prof. Yemane Berhane, Dr. Worku a., Dr. Abebe Bejiga. National Survey on Blindness, Low Vision and Trachoma in Ethiopia with support from and in collaboration with a consortium of NGOs, Ophthalmological Society of Ethiopia, and the Ethiopian Public Health Association. Addis Ababa, Ethiopia. 2006.

36. Abdou A., Nassirou B., Kadri B. et al. Prevalence and risk factors for trachoma and ocular Chlamydia trachomatis infection in Niger. BJO, 2007: 91: P 5.

37. Solomon. Magnitude and Causes of Childhood Blindness and Severe Visual Impairment in Sekoru District of Jimma Zone, South West Ethiopia: Project report. The Key Informant Method. London School of hygiene and tropical medicine. 2008-2009. 
38. MetadelAlemayehu, Digsu N. Koye, Amare Tariku, and KedirYimam. Prevalence of active trachoma and its associated factors among rural and urban children in dera district, northwest Ethiopia: a comparative cross-sectional study. Hindawi Publishing Corporation. BioMed Research International. 2015.

39. Molla Gedefaw et al. Current state of active trachoma among elementary school students in the context of ambitious national growth plan: The case of Ethiopia. Health. 2013: 5.

40. Michael J Mahande, Humphrey D Mazigo and Eliningaya J Kweka. Association between water related factors and active trachoma in Hai district, Northern Tanzania. Infectious diseases of poverty. 2012: 1:10. P 7.

41. House J. Improve WATSAN and eliminate blinding trachoma. International Conference Abuja, Nigeria. 2003.

42. Jeremiah Ngondi eta l. Risk factors for active trachoma in children and trichiasis in adults: a household survey in Amhara Regional State, Ethiopia. Science Direct, Transactions of the Royal Society of Tropical Medicine and Hygiene. 2008: 102. P 7.

43. Kubra Gobeze Ahmed, Prof (Dr.) P. Surender Reddy, Yeshimebet Ali, and Shambel Wodajo. Prevalence of Active Trachoma and its Associated Factors among Children Aged 1-9 Years in Dessie City Administration, Amhara Region, Ethiopia. Global journal for research analysis (GJRA). 2016: 5(4), ISSN No 2277 - 8160

44. Carter center. Women and Trachoma, Achieving Gender Equity in the Implementation of SAFE implementation. 2009.

\section{Tables}

Table 1: The socio-demographic and related factors of households in the study of Prevalence and risk factors of active trachoma among rural preschool children in Wadla district, Northern Ethiopia, 2016/17, $(n=499)$. 


\begin{tabular}{|c|c|c|}
\hline Variables & Frequency $(\mathrm{n}=499)$ & Percent (\%) \\
\hline \multicolumn{3}{|l|}{ Sex of head of Household } \\
\hline Male & 383 & 76.8 \\
\hline Female & 116 & 23.2 \\
\hline \multicolumn{3}{|c|}{ Marital status of head of household } \\
\hline Married & 492 & 98.6 \\
\hline Divorce & 7 & 1.4 \\
\hline \multicolumn{3}{|l|}{ Social Class or status of household } \\
\hline Poor & 144 & 28.9 \\
\hline Medium & 279 & 55.9 \\
\hline Rich & 76 & 15.2 \\
\hline \multicolumn{3}{|c|}{ Occupation of head of house hold } \\
\hline Farmer & 466 & 93.4 \\
\hline Merchant & 17 & 3.4 \\
\hline Government employee & 16 & 3.2 \\
\hline \multicolumn{3}{|c|}{ Educational status of head of household } \\
\hline Unable to read and write & 325 & 65.1 \\
\hline Able to read and write & 109 & 21.8 \\
\hline Up to grade 8 & 35 & 7 \\
\hline Grade 9-12 & 19 & 3.8 \\
\hline Diploma and above & 11 & 2.2 \\
\hline \multicolumn{3}{|l|}{ Educational status of mothers } \\
\hline Unable to read and write & 380 & 76.2 \\
\hline Able to read and write & 55 & 11 \\
\hline Up to grade 8 & 23 & 4.6 \\
\hline Grade 9-12 & 35 & 7 \\
\hline Diploma & 6 & 1.2 \\
\hline \multicolumn{3}{|l|}{ Number of rooms } \\
\hline One & 424 & 85 \\
\hline Two and More & 75 & 15 \\
\hline \multicolumn{3}{|l|}{ Family Size } \\
\hline Less than 6 & 286 & 57.3 \\
\hline Greater than/Equal to 6 & 213 & 42.7 \\
\hline \multicolumn{3}{|c|}{ Total number of children less than five years in the house } \\
\hline One & 424 & 85 \\
\hline Two & 69 & 13.8 \\
\hline Three & 6 & 1.2 \\
\hline \multicolumn{3}{|c|}{ Number of children less than ten years in the house } \\
\hline One & 132 & 26.5 \\
\hline Two & 240 & 48.1 \\
\hline Three & 102 & 20.4 \\
\hline Four & 25 & 5 \\
\hline \multicolumn{3}{|l|}{ Adult Face washing habit } \\
\hline At least one times per a day & 417 & 83.6 \\
\hline Less than 7 times per week & 82 & 16.4 \\
\hline
\end{tabular}


Table 2: The socio-demographic characteristics of children on the prevalence and risk factors of active trachoma among rural preschool children in Wadla district, North East Ethiopia, 2017, $(\mathrm{n}=596)$

\begin{tabular}{|c|c|c|}
\hline Variables & Frequency $(\mathrm{n}=596)$ & Percent \\
\hline \multicolumn{3}{|l|}{ Sex of children } \\
\hline Male & 301 & 50.5 \\
\hline Female & 295 & 49.5 \\
\hline \multicolumn{3}{|l|}{ Age of children in months } \\
\hline $12-24$ & 208 & 34.9 \\
\hline $25-36$ & 102 & 17.10 \\
\hline $37-48$ & 129 & 21.6 \\
\hline $49-59$ & 157 & 26.3 \\
\hline \multicolumn{3}{|l|}{ Current breast-feeding status of children } \\
\hline Yes & 239 & 40.1 \\
\hline No & 357 & 59.9 \\
\hline \multicolumn{3}{|l|}{ Face washing frequency of children } \\
\hline 2 or more times per a day & 108 & 18.1 \\
\hline Once daily & 79 & 13.3 \\
\hline 2 to 6 times per week & 149 & 25 \\
\hline Once weekly & 167 & 28 \\
\hline Stays unwashed for longer than a week. & 93 & 15.6 \\
\hline \multicolumn{3}{|c|}{ Habit of child bathing for at least one times per a week } \\
\hline Yes & 445 & 74.7 \\
\hline No & 151 & 25.3 \\
\hline \multicolumn{3}{|l|}{ Use of soap for face washing } \\
\hline Yes & 264 & 44.3 \\
\hline No & 332 & 55.7 \\
\hline \multicolumn{3}{|l|}{ Use of soap for hand washing } \\
\hline Yes & 254 & 42.6 \\
\hline No & 342 & 57.4 \\
\hline \multicolumn{3}{|l|}{ Face of children on observation } \\
\hline Clean face & 280 & 47 \\
\hline Ocular discharge & 89 & 14.9 \\
\hline Nasal discharge & 75 & 12.6 \\
\hline Flies on the face of child & & 10.6 \\
\hline Ocular and nasal discharge & 34 & 5.7 \\
\hline Ocular $\&$ nasal discharge $\&$ flies on the face & 55 & 9.2 \\
\hline \multicolumn{3}{|l|}{ Presence of other eye problem } \\
\hline Yes & 146 & 24.5 \\
\hline No & 450 & 75.5 \\
\hline \multicolumn{3}{|l|}{ Type of eye problem $(n=146)$} \\
\hline Discharge & 96 & 65.6 \\
\hline Itching & 8 & 5.3 \\
\hline Excessive tear & 25 & 17.1 \\
\hline Redness of eye & 18 & 12.2 \\
\hline \multicolumn{3}{|c|}{ Took drug during mass drug administration in the last year } \\
\hline Yes & 515 & 86.4 \\
\hline No & 81 & 13.6 \\
\hline
\end{tabular}




\begin{tabular}{|c|c|c|c|c|}
\hline \multirow[b]{2}{*}{ Variables } & \multicolumn{2}{|c|}{ Trachoma $(n=596)$} & \multicolumn{2}{|c|}{ OR $(95 \% \mathrm{CI})$} \\
\hline & Presence (\%) & Absence (\%) & COR & AOR \\
\hline \multicolumn{5}{|l|}{ House roof } \\
\hline Clean iron & 15 (11.5) & $82(17.6)$ & 1.00 & 1.00 \\
\hline Thatch iron & $24(18.5)$ & $141(30.3)$ & $0.9(0.5-1.9)$ & $0.9(0.3-2.8)$ \\
\hline Clean grass & $27(20.8)$ & $144(30.9)$ & $1.0(0.5-2.0)$ & $0.7(0.2-2.2)$ \\
\hline Thatch grass & $64(49.2)$ & $99(21.2)$ & $3.5(1.9-6.7) *$ & $4.4(1.4-13.6) *$ \\
\hline \multicolumn{5}{|l|}{ Fly in near House } \\
\hline Yes & $96(73.8)$ & $206(44.2)$ & $3.6(2.3-5.5)$ & $4.6(2.1-9.9) *$ \\
\hline No & $34(26.2)$ & $260(55.8)$ & 1.00 & 1.00 \\
\hline \multicolumn{5}{|l|}{ Face washing frequency } \\
\hline Two/more times & $9(6.9)$ & $99(21.2)$ & 1.00 & 1.00 \\
\hline Once daily & $2(1.5)$ & 77 (16.5) & $0.3(0.1-1.4)$ & $0.2(0.03-1.3)$ \\
\hline 2-6 times per week & 15 (11.5) & $134(28.8)$ & $1.2(0.5-2.9)$ & $1.366(.365-5.114)$ \\
\hline Once weekly & $63(48.5)$ & $104(22.3)$ & $6.7(3.1-14.1) *$ & $8.7(2.6-29.3) *$ \\
\hline Unwashed for a week. & $41(31.5)$ & $52(11.2)$ & $8.7(3.9-19.2) *$ & $10.6(2.9-37.7) *$ \\
\hline \multicolumn{5}{|l|}{ Soap for face washing } \\
\hline Used & $26(20)$ & $238(51.1)$ & 1.00 & 1.00 \\
\hline Not used & $104(80)$ & $228(48.9)$ & $4.2(2.6-6.7) *$ & $4.5(1.8-11.3) *$ \\
\hline \multicolumn{5}{|l|}{ Soap for hand washing } \\
\hline Used & $35(26.9)$ & $219(47.0)$ & 1.00 & 1.00 \\
\hline Not used & $95(73.1)$ & $247(53.0)$ & $2.4(1.6-3.7) *$ & $1.6(0.8-3.6)$ \\
\hline \multicolumn{5}{|l|}{ Household Latrine } \\
\hline Present & & $364(78.1)$ & 1.00 & 1.00 \\
\hline Absent & & $102(21.9)$ & $2.0(1.3-3.0) *$ & $5.0(2.0-12.9) *$ \\
\hline \multicolumn{5}{|l|}{ Waste around house } \\
\hline Exist & $80(61.5)$ & $214(45.9)$ & $1.9(1.3-2.8) *$ & $3.4(1.6-7.6) *$ \\
\hline Not exist & 50 (38.5) & $252(54.1)$ & 1.00 & 1.00 \\
\hline \multicolumn{5}{|l|}{ Place of cooking } \\
\hline Within the house & $102(78.5)$ & $295(63.3)$ & $2.1(1.3-3.3) *$ & $1.3(0.6-2.9)$ \\
\hline Out of house & $28(21.5)$ & $171(36.7)$ & 1.00 & 1.00 \\
\hline
\end{tabular}




\begin{tabular}{|c|c|c|c|c|}
\hline \multirow[b]{2}{*}{ Variables } & \multicolumn{2}{|c|}{ Trachoma $(n=596)$} & \multicolumn{2}{|c|}{ OR $(95 \% \mathrm{CI})$} \\
\hline & Presence (\%) & Absence (\%) & COR & AOR \\
\hline \multicolumn{5}{|l|}{ House roof } \\
\hline Clean iron & $15(11.5)$ & $82(17.6)$ & 1.00 & 1.00 \\
\hline Thatch iron & 24 (18.5) & $141(30.3)$ & $0.9(0.5-1.9)$ & $0.9(0.3-2.8)$ \\
\hline Clean grass & $27(20.8)$ & $144(30.9)$ & $1.0(0.5-2.0)$ & $0.7(0.2-2.2)$ \\
\hline Thatch grass & $64(49.2)$ & $99(21.2)$ & $3.5(1.9-6.7) *$ & $4.4(1.4-13.6) *$ \\
\hline \multicolumn{5}{|l|}{ Fly in near House } \\
\hline Yes & $96(73.8)$ & $206(44.2)$ & $3.6(2.3-5.5)$ & $4.6(2.1-9.9) *$ \\
\hline No & $34(26.2)$ & $260(55.8)$ & 1.00 & 1.00 \\
\hline \multicolumn{5}{|l|}{ Face washing frequency } \\
\hline Two/more times & $9(6.9)$ & $99(21.2)$ & 1.00 & 1.00 \\
\hline Once daily & $2(1.5)$ & 77 (16.5) & $0.3(0.1-1.4)$ & $0.2(0.03-1.3)$ \\
\hline 2-6 times per week & $15(11.5)$ & $134(28.8)$ & $1.2(0.5-2.9)$ & $1.366(.365-5.114)$ \\
\hline Once weekly & $63(48.5)$ & $104(22.3)$ & $6.7(3.1-14.1) *$ & $8.7(2.6-29.3) *$ \\
\hline Unwashed for a week. & $41(31.5)$ & $52(11.2)$ & $8.7(3.9-19.2) *$ & $10.6(2.9-37.7) *$ \\
\hline \multicolumn{5}{|l|}{ Soap for face washing } \\
\hline Used & $26(20)$ & $238(51.1)$ & 1.00 & 1.00 \\
\hline Not used & $104(80)$ & $228(48.9)$ & $4.2(2.6-6.7) *$ & $4.5(1.8-11.3) *$ \\
\hline \multicolumn{5}{|l|}{ Soap for hand washing } \\
\hline Used & 35 (26.9) & $219(47.0)$ & 1.00 & 1.00 \\
\hline Not used & $95(73.1)$ & $247(53.0)$ & $2.4(1.6-3.7) *$ & $1.6(0.8-3.6)$ \\
\hline \multicolumn{5}{|l|}{ Household Latrine } \\
\hline Present & & $364(78.1)$ & 1.00 & 1.00 \\
\hline Absent & & $102(21.9)$ & $2.0(1.3-3.0) *$ & $5.0(2.0-12.9) *$ \\
\hline \multicolumn{5}{|l|}{ Waste around house } \\
\hline Exist & $80(61.5)$ & $214(45.9)$ & $1.9(1.3-2.8) *$ & $3.4(1.6-7.6) *$ \\
\hline Not exist & $50(38.5)$ & $252(54.1)$ & 1.00 & 1.00 \\
\hline \multicolumn{5}{|l|}{ Place of cooking } \\
\hline Within the house & $102(78.5)$ & $295(63.3)$ & $2.1(1.3-3.3) *$ & $1.3(0.6-2.9)$ \\
\hline Out of house & $28(21.5)$ & $171(36.7)$ & 1.00 & 1.00 \\
\hline
\end{tabular}

Table 3: The bi-variable and multi-variable logistic regression for the presence of association between active trachoma and environmental as well as related factors on the title prevalence and risk factors of active trachoma among rural preschool children in Wadla district, Northern Ethiopia, 2016/17

Note: "*” = P - value less than 0.001 and “**” = P - value less than 0.05 on bi-variable analysis 


\section{Figures}

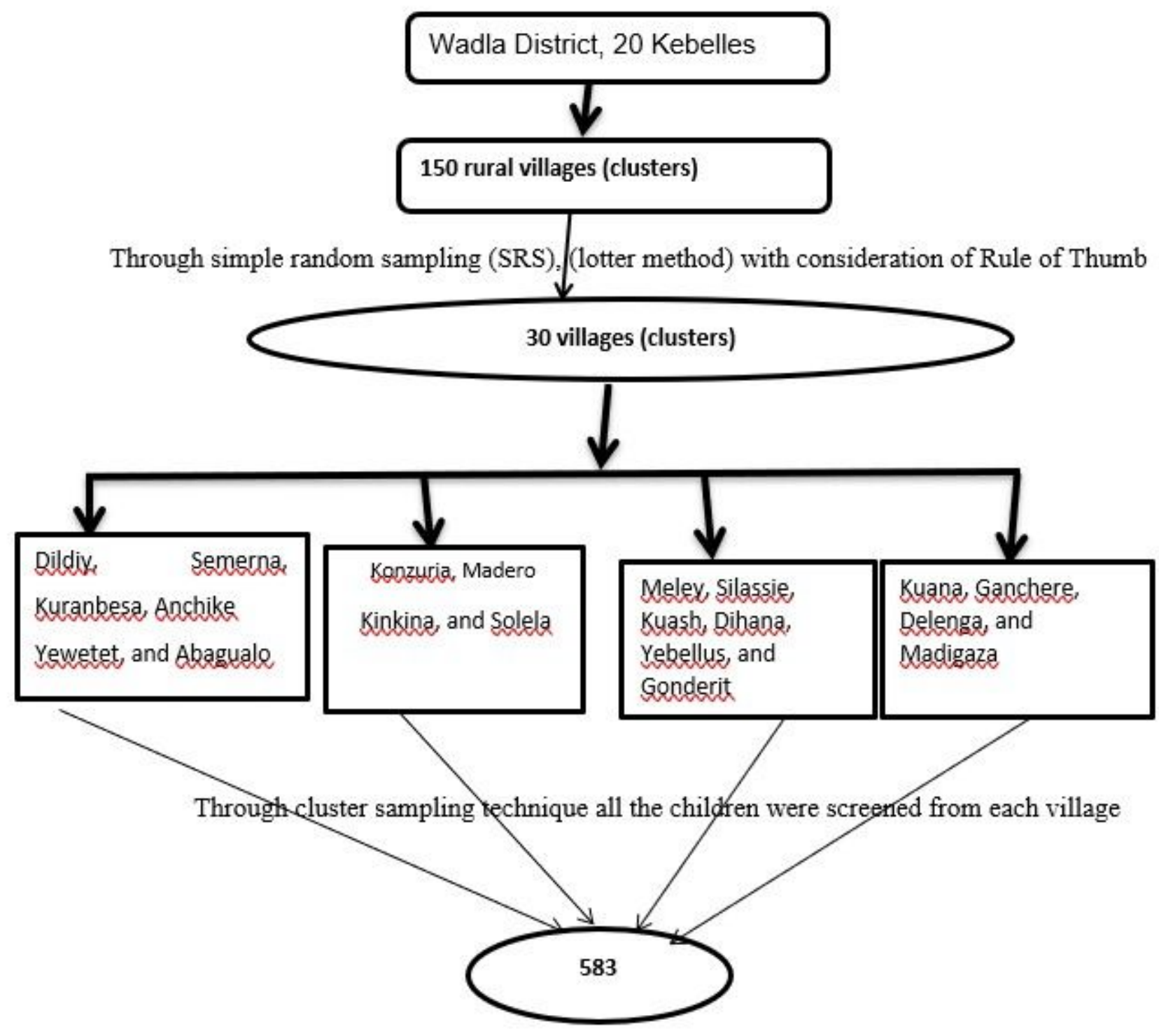

Figure 1

Schematic presentation of Sampling Selection Procedure for the study on the prevalence and risk factors of active trachoma among rural preschool children in Wadla district, North Wollo zone, Amhara region, north east Ethiopia, 2016/17.

\section{Supplementary Files}


This is a list of supplementary files associated with this preprint. Click to download.

- STROBE.docx

- Tables2.docx

- Tables1.docx

- PointPointResponseBMC.docx 